\title{
BMJ Open The Schulthess local Shoulder Arthroplasty Registry (SAR): cohort profile
}

\author{
Alex Marzel (D) , ${ }^{1,2}$ Hans-Kaspar Schwyzer, ${ }^{2}$ Christoph Kolling, ${ }^{2}$ Fabrizio Moro, ${ }^{2}$ \\ Matthias Flury, ${ }^{3}$ Michael C Glanzmann, ${ }^{2}$ Christian Jung, ${ }^{2}$ Barbara Wirth, ${ }^{2}$ \\ Beatrice Weber, ${ }^{1}$ Beat Simmen, ${ }^{4}$ Markus Scheibel, ${ }^{2,5}$ Laurent Audigé (i) ${ }^{1}$
}

To cite: Marzel A, Schwyzer H-

$\mathrm{K}$, Kolling $\mathrm{C}$, et al. The

Schulthess local Shoulder Arthroplasty Registry (SAR): cohort profile. BMJ Open 2020;10:e040591. doi:10.1136/ bmjopen-2020-040591

- Prepublication history and additional materials for this paper is available online. To view these files, please visit the journal online (http://dx.doi org/10.1136/bmjopen-2020040591).

AM and $\mathrm{H}-\mathrm{KS}$ contributed equally.

Received 18 May 2020 Revised 06 October 2020 Accepted 05 November 2020

Check for updates

(C) Author(s) (or their employer(s)) 2020. Re-use permitted under CC BY-NC. No commercial re-use. See rights and permissions. Published by BMJ.

${ }^{1}$ Research, Teaching and Development, Schulthess Klinik, Zurich, Switzerland

${ }^{2}$ Shoulder and Elbow Surgery, Schulthess Klinik, Zurich,

Switzerland

${ }^{3}$ Center for Orthopaedics and Neurosurgery, In Motion, Zurich, Switzerland

${ }^{4}$ Endoclinic, Hirslanden Clinic, Zurich, Switzerland

${ }^{5}$ Center for Musculoskeletal

Surgery, Charité

Universitätsmedizin, Berlin, Germany

Correspondence to Professor Laurent Audigé; laurent.audige@kws.ch

\section{ABSTRACT}

Purpose Clinical registries are essential for evaluation of surgical outcomes. The Schulthess Shoulder Arthroplasty Registry (SAR) was established in 2006 to evaluate safety, function, quality-of-life and patient satisfaction in patients undergoing shoulder arthroplasty.

Participants Adult patients undergoing anatomic or reverse shoulder joint replacement at the Schulthess Klinik, a high-volume, leading orthopaedic surgery centre in Zürich, Switzerland.

Findings to date Between March 2006 and December 2019 , the registry covered $98 \%$ of eligible operations. Overall, 2332 patients were enrolled with a total of 2796 operations and 11147 person-years of follow-up. Mean age at baseline was 71 (range: 20-95), 65\% were women. Most common indication was rotator cuff tears with osteoarthritis $(42 \%)$ and the mean preoperative Constant Score was $31( \pm 15)$. The most frequent arthroplasty type was reverse, increasing from $61 \%$ in 2006-2010 to $86 \%$ in 2015-2019. Functional recovery peaked at 12-month postoperatively and did not show a clinically relevant deterioration during the first ten follow-up years. Since its establishment, the registry was used to address multiple pertinent clinical and methodological questions. Primary focus was on comparing different implant configurations (eg, glenosphere diameter) and surgical techniques (eg, latissimus dorsi transfer) to maximise functional recovery. Additionally, the cohort contributed to the determination of the clinical relevance and validity of radiological monitoring of cortical bone resorption and scapular notching. Finally, SAR data helped to demonstrate that returning to sports was among key patient expectations after reverse shoulder arthroplasty.

Future plans As first patients are approaching the 15 years follow-up landmark, the registry will continue providing essential data on long-term functional outcomes, implant stability, revision rates and aetiologies as well as patient satisfaction and quality-of-life. In addition to research and quality-control, the cohort data will be brought back to the patients by bolstering real-time clinical decision support.

\section{INTRODUCTION}

Shoulder joint replacement is indicated for osteoarthritis, inflammatory arthritis, proximal humerus fractures, irreparable rotator
Strengths and limitations of this study

- Main strengths are high coverage, a detailed description of the operation by the surgeon, use of validated outcome tools and internationally accepted core sets, consistent clinical, patient-reported and radiographic follow-up, and a long follow-up time with some patients approaching the 15 years follow-up landmark.

- One weakness of the cohort is lack of linkage with exact data on deaths which makes the distinction between deceased and lost to follow-up challenging.

- Currently there is no systematic evaluation of the postoperative physical therapy.

- Progressively deteriorating general and cognitive health naturally diminishes long-term follow-up and retention rates.

cuff tears, rotator cuff arthropathy and avascular necrosis of the humeral head. ${ }^{12}$ Despite generally excellent pain reduction and function restoration, the patients may experience one or several complications, ${ }^{3}$ including; prosthetic loosening, glenohumeral instability, periprosthetic fracture, rotator cuff tears, nerve injury, infection and deltoid muscle dysfunction. ${ }^{4}$ As a result of an increasing market demand in recent years, a plethora of different implants designs, configurations and combinations has emerged ${ }^{56}$ requiring more long-term prospective studies on safety and functional recovery. These studies require clinical registries with high-quality prospective data. When compared with large national registries, which demand complex coordination and large resources, ${ }^{7}$ local registries often have an advantage of possessing better means to encourage active participation and complete reporting.

The Schulthess local Shoulder Arthroplasty Registry is located at the Schulthess Klinik, an international high-volume orthopaedic centre in Zürich, Switzerland, serving also as a 
Swiss Olympic Medical Centre. The cohort was established to evaluate safety, function, quality-of-life and patient satisfaction in patients undergoing anatomic or reverse shoulder arthroplasty (RSA). The main focus was set on predictive and risk factors for functional recovery, ${ }^{8-10}$ device-related adverse events (AEs) and revisions as well as early screening of radiological pathologies. ${ }^{11}$ Weight was also given to subjective patient-reported outcome measures. ${ }^{12}$ The cohort is continuously funded by the Wilhelm Schulthess Foundation and by nested projects with industry partners. The aim of the current Cohort Profile is to describe the structure and the baseline characteristics of this registry, and to share the collected technical end epidemiological experience in establishing and maintaining a shoulder replacement registry with a high coverage and good publication output. Additionally, as most Cohort Profiles we also aim: (i) to promote standardisation across cohorts by allowing comparison between data collection procedures; (ii) to enable comparison between study populations by comparing baseline characteristics; (iii) to allow clinical papers to concentrate on hypothesis testing and minimising self-plagiarism in the Methods section; (iv) to facilitate collaborations and promote establishment of consortiums. ${ }^{13}$

\section{COHORT DESCRIPTION}

Inclusion criteria and target population coverage

A prospective cohort of adult patients undergoing anatomic or reverse shoulder joint replacement, or an implant revision, at the Schulthess Klinik, Zürich, Switzerland.

The coverage of the registry is determined by dividing the registered cases by all the eligible cases in the hospital billing system. The overall (March 2006 to December 2019) coverage was $98 \%(2796 / 2860$, figure 1$)$. After excluding the initiation phase of the first 6 months, the coverage is $99 \%(2765 / 2782)$. This consistently high coverage can be attributed to three factors: (i) technological solution (implemented in FileMaker Pro Advanced (V.18, Claris International, California, USA)) that flags each prosthesis implantation for the cohort staff the moment the operation is scheduled in the electronic clinical record; (ii) sufficient funding for study assistance and data management that allows close operation plan monitoring; (iii) high motivation and commitment of the surgeons for quality control and scientific activities.

\section{Operation documentation and follow-up timepoints}

The operation is documented in detail by the operating surgeon including the primary indication, the surgical approach, the intraoperative evaluation of the rotator cuff tendons, the used prosthesis type and configuration as well as additional surgical procedures (ie, tubercle refixation, biceps tenotomy/tenodesis, muscle transfer, metal removal, bone graft, osteosynthesis, acromio-clavicular resection, acromioplasty, tubercleplasty) and intraoperative AEs. Clinical and functional examinations, assessment

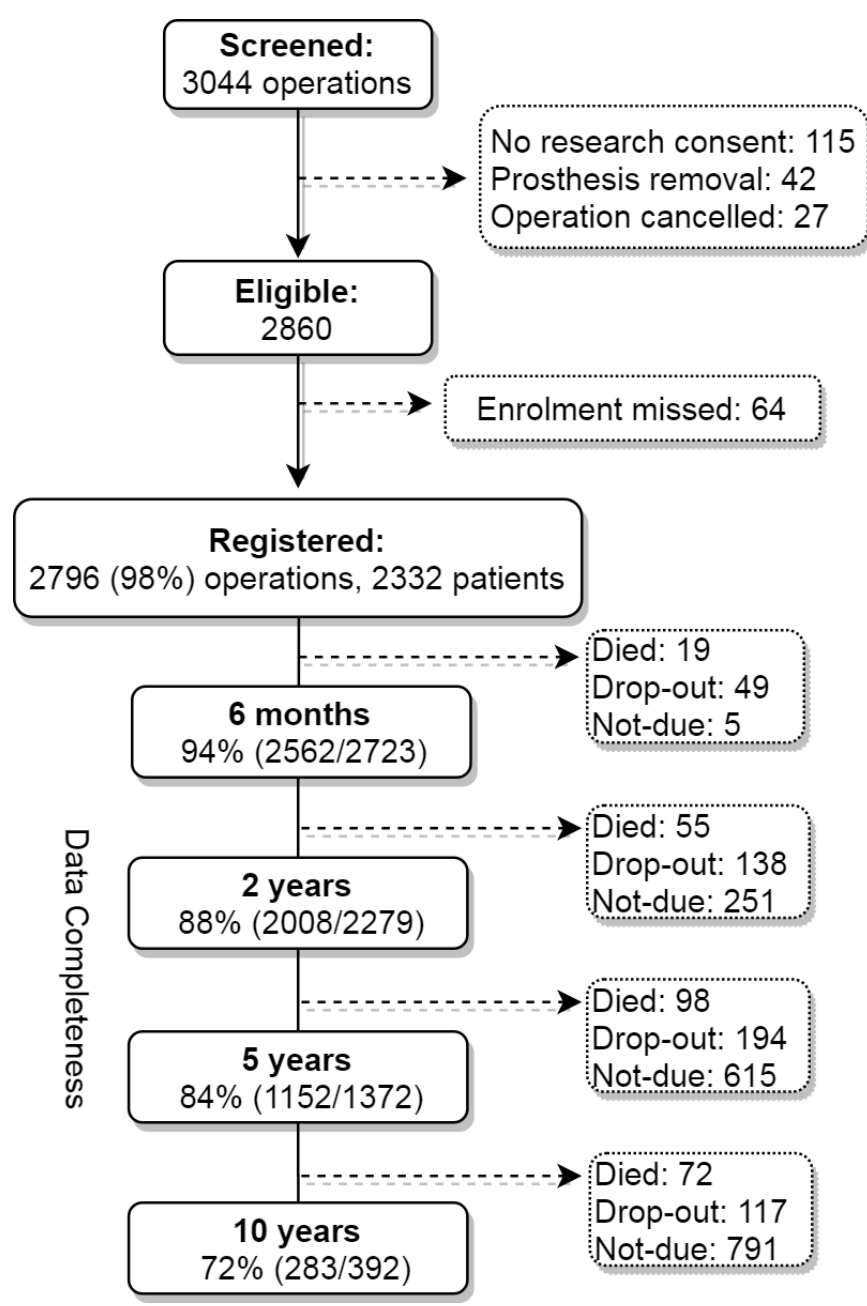

Figure 1 Cohort inclusion flow-chart, March 2006 to December 2019. For each timepoint, data completeness is calculated as number of cases that have either available clinical examination or a filled patient questionnaire, out of all expected cases for this timepoint.

of AEs and radiology are performed at presurgery and then at 6 months, 1 year (optional), 2 years, 5 years, 10 years and 15 years (figure 2). After 5 years, follow-up is expected to proceed in 5 -years intervals until revision of the prosthesis or patient dropout from the registry for any reason including deteriorating general health and death. Prior to each clinical visit all patients receive questionnaires to assess patient reported outcomes. The questionnaires are mailed together with a prepaid return envelope. Recently, a transition to electronic questionnaires which are distributed via emails was successfully tested with a subset of willing participants.

\section{Assessment of shoulder function, quality-of-life and patient satisfaction}

At each clinical examination the following active and passive range of motion parameters are evaluated; flexion, abduction, internal and external rotation at $90^{\circ}$ and external rotation at $0^{\circ}$. In addition, the Apley scratch test, ${ }^{14}$ drop-arm sign, lag sign, Hornblower sign, lift-off and the Belly-Press tests are performed. ${ }^{15}$ Abduction 


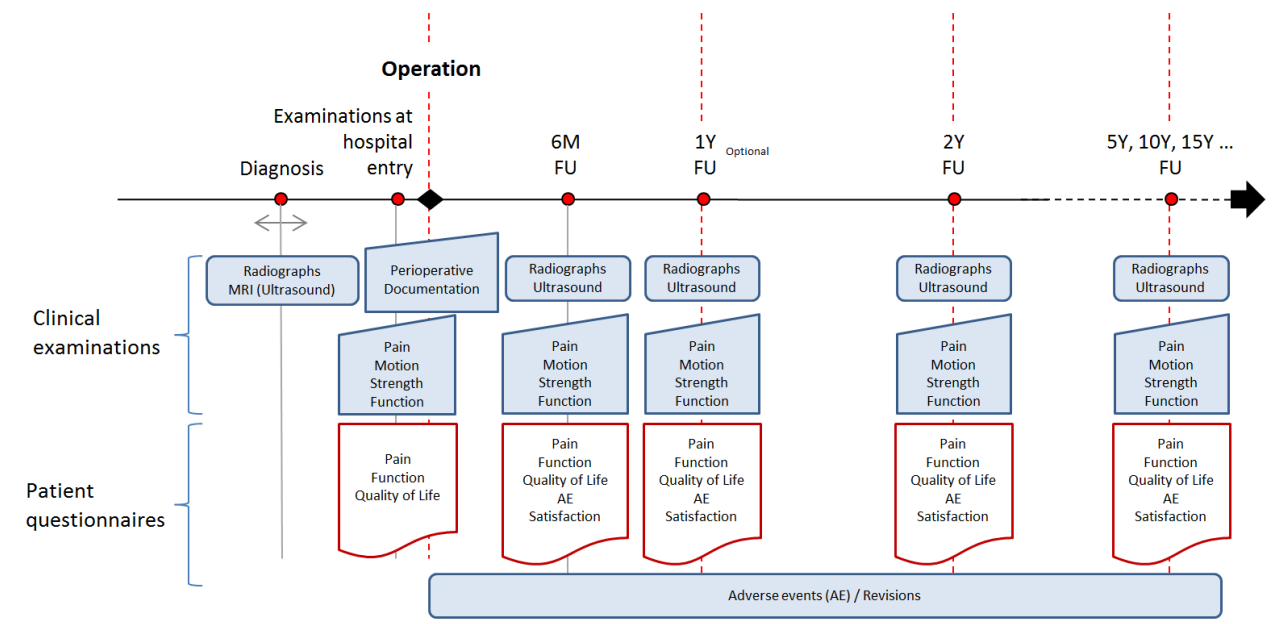

Figure 2 Documentation procedures of the Schulthess Shoulder Arthroplasty Registry.

strength of both arms is measured using a spring balance (Pesola, Schindellegi, Switzerland).

Shoulder functional outcomes are assessed with four validated instruments; the Constant Score (CS),${ }^{1617}$ Quick Disabilities of Arm, Shoulder and Hand (QuickDASH) score ${ }^{18-20}$ Shoulder Pain and Disability Index (SPADI) ${ }^{21}$ and the Subjective Shoulder Value (SSV). ${ }^{22}$ Quality of life is assessed with EuroQol Visual Analogue Scale (EQ-VAS) $(0=\text { worse, } 100=\text { best })^{23}$ and EuroQoL 5-dimension 5-level (EQ-5D-5L). ${ }^{24}{ }^{25}$ Patients are also asked whether they would agree to undergo the same operation again and to what extent their situation changed as compared with preoperation in terms of shoulder function and qualityof-life (5-levels ranging from 'much better' to 'much worse'). Finally, the patients are asked to what extent their overall expectations of the operation were fulfilled $(0=$ not at all; $10=$ fully $)$.

\section{Assessment of AEs}

AEs and complications are assessed according to the published international core set of unfavourable events of shoulder arthroplasty. ${ }^{26}$ Timeframe of occurrence (intraoperative or postoperative), site (local or systemic), whether the event is a Serious AE, the affected tissues or physiological systems, possible relation to implant and the $\mathrm{AE}$ treatment and $\mathrm{AE}$ outcome are all documented. ${ }^{27}$ Revision operations are documented in detail ${ }^{28}$ including reasons (infection, glenoid periprosthetic fracture, humeral periprosthetic fracture, dislocation/instability, glenoid component loosening, humeral component loosening, rotator-cuff problems, prosthesis failure, other reasons). Death is passively reported by the relatives and the family physician. In addition, when a follow-up time point is due, the study assistant tries to contact the patient twice by phone on two different dates. If unsuccessful, the family physician is contacted. Finally, publicly accessible sources, like obituary websites are also consulted.

\section{Radiographic and ultrasound monitoring}

Pathological radiological changes are evaluated according to the international core set of radiological parameters for shoulder arthroplasty monitoring. ${ }^{29}$ It is a standardised protocol for an image-based monitoring process following shoulder arthroplasty. The main evaluated parameters are: implant migration (subsidence, tilt, shift); radiolucency around the implant and implant loosening; signs of shoulder joint displacement; bone resorption and formation; wear of the implant articular surfaces; fractures around the implant; implant breakage and disassembly. Up to December 2019, tendons assessments via ultrasound was systematically performed only for anatomic implants. Starting from January 2020, ultrasound is performed for both anatomic and reverse implants.

\section{Data management and monitoring}

Cohort data are collected using REDCap (Research Electronic Data Capture) tools hosted at Schulthess Klinik. ${ }^{30}$ REDCap is a secure, web-based application designed to support data capture for research studies, providing: (i) an intuitive interface for validated data entry; (ii) audit trails for tracking data manipulation and export procedures; (iii) automated export procedures for seamless data downloads to common statistical packages; and (iv) procedures for importing data from external sources. Enrolment and routine monitoring are performed with a help of a secured designated FileMaker Pro Advanced (V.18, Claris International) database connected to the clinic information system via an SQL server. Demographic data and key operation parameters are periodically imported from the SQL server into the REDCap server. The operation form is filled online by the operating surgeon, immediately upon completion of the operation.

The cohort analytical unit of follow-up is an implant, not a person. This is necessary since one person can have bilateral implants or multiple revisions of an ipsilateral shoulder. When a revision with a component replacement takes place, an $\mathrm{AE}$ is documented on the old prosthesis number, which becomes a dropout, and a new registry case is opened for the new implant. Quarterly statistical monitoring and data completeness checks are performed 
with STATA (V.14) and R (V.3.6.2, R Foundation for Statistical Computing, Vienna, Austria). When possible, missing data are completed retrospectively as part of a routine quality control.

\section{PATIENT CHARACTERISTICS AND GENERALISABILITY}

Overall, 2332 patients were enrolled with a total of 2796 operations and 11147 person-years. Mean age at baseline was 71 (range: 20-95), 65\% were women and $46 \%$ had a severe systemic disease (ASA class 3), table 1. Mean CS, SPADI and SSV at baseline were 31, 36 and 40, respectively. Mean preoperative pain was $5.8( \pm 2.6$, scale $(0=$ no pain, $10=$ maximum pain)) and mean QuickDASH score was $53( \pm 18.2)$. The most common indication was rotator cuff tears with osteoarthritis $(42 \%)$, followed by primary osteoarthritis $(23 \%)$. The most frequent arthroplasty type was reverse, increasing from $61 \%$ in 2006-2010 to $86 \%$ in 2015-2019 (Fisher's exact $\mathrm{p}<0.001$, figure 3). The most frequent prosthesis has changed over time from Lima Reverse in 2006 to Univers Revers in 2019 (figure 4). Fourteen per cent of the patients received a bilateral implant during the follow-up. Overall, 19 different surgeons contributed to the study along the years. This fact combined with a large range of operation indications (table 1) including both chronic conditions (eg, cuff tear arthropathy) and trauma (fractures) as well as the wide range of used implants, all speak for the generalisability of our cohort.

\section{Functional outcomes over time}

Both for reverse and anatomic implants the peak of recovery as measured by CS and SPADI is reached within the first 12 months postoperatively (figure 5). The result then remains relatively stable over the first 10 years without a clinically significant functional deterioration.

\section{Dropouts, data completeness and revision rates}

The overall dropout (death, lost to follow-up and noncompliance but excluding revisions) rate was 0.052 per implant and year, corresponding to a dropout percentage of $23 \%$ at 5 years and $41 \%$ at 10 years, which is expected in a population of older adults with a high comorbidity burden. Considering the mean age of 71 at baseline, this 10 years dropout rate is in line with the reported for hip ${ }^{31}$ and knee ${ }^{32}$ arthroplasty, and with the Swiss healthy life years at age 65 of 10 years. ${ }^{33}$ This is substantiated by a higher prevalence of severe comorbidities (ASA class 3 and 4) among the dropouts in comparison to remaining participants $(60 \%$ vs $45 \%$, Fisher's exact $\mathrm{p}<0.001)$. For the latter, data completeness was higher for short-term follow-up timepoints and decreased at later timepoints, with $94 \%$ having a documented follow-up (either physical examination or a filled questionnaire) at 6 months, $88 \%$ at 2 years, $84 \%$ at 5 years and $72 \%$ at 10 years follow-up. The overall pooled revision rate was 0.0156 per implant and year, corresponding to $14 \%$ revisions 10 years postimplantation, which is in line with other studies. ${ }^{34}$
Table 1 Demographic and clinical characteristics of cohort participants at first operation

\begin{tabular}{|c|c|c|}
\hline & N (\%) & Mean (SD) \\
\hline Age & 2332 & $71(10.3)$ \\
\hline \multicolumn{3}{|l|}{ Age category } \\
\hline$\leq 60$ & 311 (13.3) & \\
\hline $61-70$ & $610(26.2)$ & \\
\hline$>70$ & $1411(60.5)$ & \\
\hline \multicolumn{3}{|l|}{ Gender } \\
\hline Women & $1526(65.4)$ & \\
\hline Men & 806 (34.6) & \\
\hline \multicolumn{3}{|l|}{ Insurance class } \\
\hline General & $929(39.8)$ & \\
\hline Semi-private & 725 (31.1) & \\
\hline Private & 678 (29.1) & \\
\hline \multicolumn{3}{|l|}{ Smoking } \\
\hline No & $1861(88.8)$ & \\
\hline Yes & $234(11.2)$ & \\
\hline BMI & 959 & $27.2(9.1)$ \\
\hline
\end{tabular}

ASA physical status classification system

$\begin{array}{lc}\text { I. Healthy patient } & 102(4.4) \\ \text { II. Mild systemic disease } & 1127(48.4)\end{array}$

III. Severe systemic disease 1075 (46.2)

IV. Severe systemic disease 23 (1)

that is a constant threat to

life

Admission type

\begin{tabular}{|c|c|c|}
\hline Illness & $1683(72.2)$ & \\
\hline Accident & $649(27.8)$ & \\
\hline \multicolumn{3}{|l|}{ Primary indication } \\
\hline $\begin{array}{l}\text { Rotator cuff tears without } \\
\text { osteoarthritis }\end{array}$ & $157(6.7)$ & \\
\hline $\begin{array}{l}\text { Rotator cuff tears with } \\
\text { osteoarthritis }\end{array}$ & $981(42.1)$ & \\
\hline Rheumatoid arthritis & $72(3.1)$ & \\
\hline Prosthesis replacement & $148(6.4)$ & \\
\hline Fresh fracture & $43(1.8)$ & \\
\hline $\begin{array}{l}\text { Post-traumatic (after } \\
\text { fracture) }\end{array}$ & $232(10)$ & \\
\hline Primary osteoarthritis & $533(22.9)$ & \\
\hline Humeral head necrosis & $47(2)$ & \\
\hline $\begin{array}{l}\text { Other secondary } \\
\text { osteoarthritis (instability, } \\
\text { infection) }\end{array}$ & $116(5)$ & \\
\hline Preoperative pain (0-10) & 2231 & $5.8(2.6)$ \\
\hline Constant Score & 2150 & $31.3(14.7)$ \\
\hline SPADI & 2143 & $36.5(19.8)$ \\
\hline QuickDASH & 2140 & $52.6(18.2)$ \\
\hline Subjective Shoulder Value ${ }^{*}$ & 905 & $40.1(20.8)$ \\
\hline Abduction & 2280 & $66.7(31.3)$ \\
\hline
\end{tabular}

Continued 
Table 1 Continued

\begin{tabular}{lcc}
\hline & N (\%) & Mean (SD) \\
\hline $\begin{array}{l}\text { Flexion } \\
\begin{array}{l}\text { Abduction strength, affected } \\
\text { arm (kg) }\end{array}\end{array}$ & 2280 & $77.6(36.4)$ \\
$\begin{array}{l}\text { Abduction strength, } \\
\text { unaffected arm (kg) }\end{array}$ & 2100 & $0.7(1.7)$ \\
\begin{tabular}{l} 
EQ-VAS $^{*}$ \\
\hline
\end{tabular} & 956 & $4.8(3.5)$ \\
\hline
\end{tabular}

Active ranges of motion are presented.

*Parameter introduced in 2014. For Constant Score, SPADI and SSV higher values represent better outcome for QuickDash lower values are better.

BMI, body mass index; EQ-VAS, EuroQol Visual Analogue Scale; QuickDASH, Quick Disabilities of Arm, Shoulder and Hand; SPADI, Shoulder Pain and Disability Index.

\section{FINDINGS TO DATE}

Since its establishment the registry was used to address several pertinent clinical and methodological questions. The large number of participants and detailed surgery documentation allowed comparison of different surgical approaches. Audigé et al outlined the expected course of postoperative shoulder pain and function in patients with anatomical or RSA following different humerus fracture sequelae, to demonstrate that both operations lead to sustained clinical improvements. ${ }^{8}$ On the other hand, Glanzmann et al showed no difference in postoperative radiological and functional outcomes 2years postoperation, between patients undergoing resurfacing total shoulder arthroplasty (TSA) as compared with those treated with a stemmed TSA. ${ }^{35}$ Although the resurfacing procedure had a significantly shorter surgery time, with the availability of new TSA implants it became obsolete.

The effect of different implant configurations on postoperative functional outcomes was also examined in the registry. Using the SAR data, it was demonstrated that an increase in glenosphere diameter leads to a clinically moderate but significant increase in external rotation in adduction and abduction strength at midterm follow-up. ${ }^{36}$ Furthermore, recently, the registry played a pivotal role in an international collaboration that determined the shortterm safety of the Univers Revers prosthesis. ${ }^{37}$

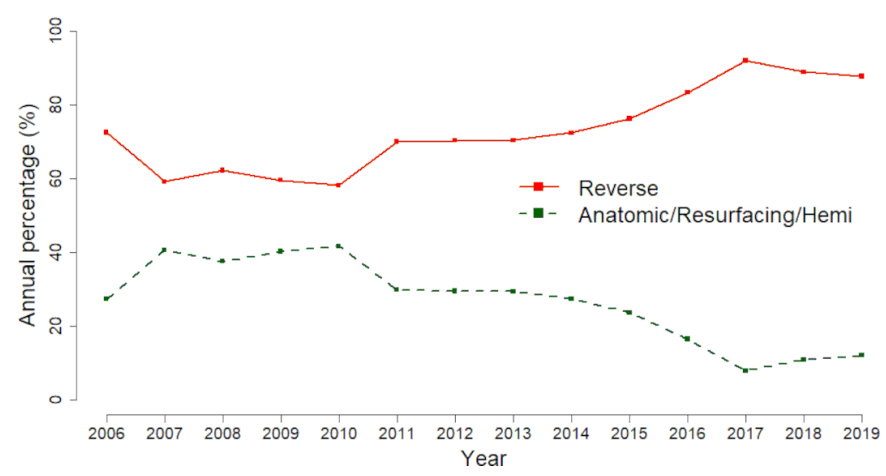

Figure 3 Annual percentages of reverse and other implants in the Schulthess Shoulder Arthroplasty Registry.
Patients undergoing RSA often maintain a deficit in external rotation which can limit activities of daily living. It was previously suggested that complementing the RSA with Latissimus dorsi muscle transfer can improve this external rotation deficit. Flury et al used SAR data to demonstrate that this additional procedure indeed reduced external rotation deficit, although this came at the cost of internal rotation and was accompanied by extended operation time and potentially increased complication risk. ${ }^{38}$

Prospective radiological assessment is an important part of postoperative implant monitoring. However, the clinical applicability of some radiological findings remains to be proven. The SAR was used to assess the timing and location of cortical bone resorption after TSA with an uncemented rectangular stem to investigate its effect on shoulder function up to 5years after implantation. ${ }^{11}$ This study showed that there was no significant negative effect of bone resorption radiological finding on functional outcome 5years after surgery. On the methodological side, the registry X-ray collection also helped to demonstrate the poor reliability of scapular notching grading based on the Sirveaux classification system using anteroposterior radiographs, hence emphasising the need in consensus among several assessors to increase reliability in research and clinical settings. ${ }^{39}$

An increasing number of patients undergo RSA on both shoulders because symptomatic rotator cuff tears are often bilateral. This bilateral RSA is still controversial because of potential rotational deficits potentially impairing activities of daily living, personal hygiene in particular. Wirth et al assessed achievement of insufficient internal rotation and associated factors in bilateral RSA patients in the SAR. ${ }^{14}$ They showed that at 2 years postoperation, only $5 \%$ of patients had insufficient internal rotation on both sides.

In addition to range of motion, another important aspect of successful rehabilitation is return to sports. Kolling et $a l$ administrated an additional questionnaire to 305 SAR patients to examine return to sports after RSA to show that $77 \%$ returned to preoperation sports activity, most with a moderate level of intensity. ${ }^{9}$ This study also demonstrated that returning to sports was among key patient expectations after RSA.

Finally, like any surgical procedure, RSA can also fail or may require revision surgery or a reintervention without a component change. ${ }^{40}$ The optimal treatment of a failed RSA remains unclear. Glanzmann et al evaluated conversion to hemiarthroplasty as a salvage procedure for failed RSA to demonstrate an overall suboptimal pain relief and poor functional outcome emphasising the need for better options. ${ }^{41}$

\section{Quality control}

Alongside with academic research activities, the cohort is also routinely used for internal quality control purposes. The primary focus is set on detecting and sorting out implants with unexpectedly high early failure rate, remaining with the best implants for our patient population. Additionally, questions about postoperative patient satisfaction help us better understand the needs of the patients and to manage expectations. 


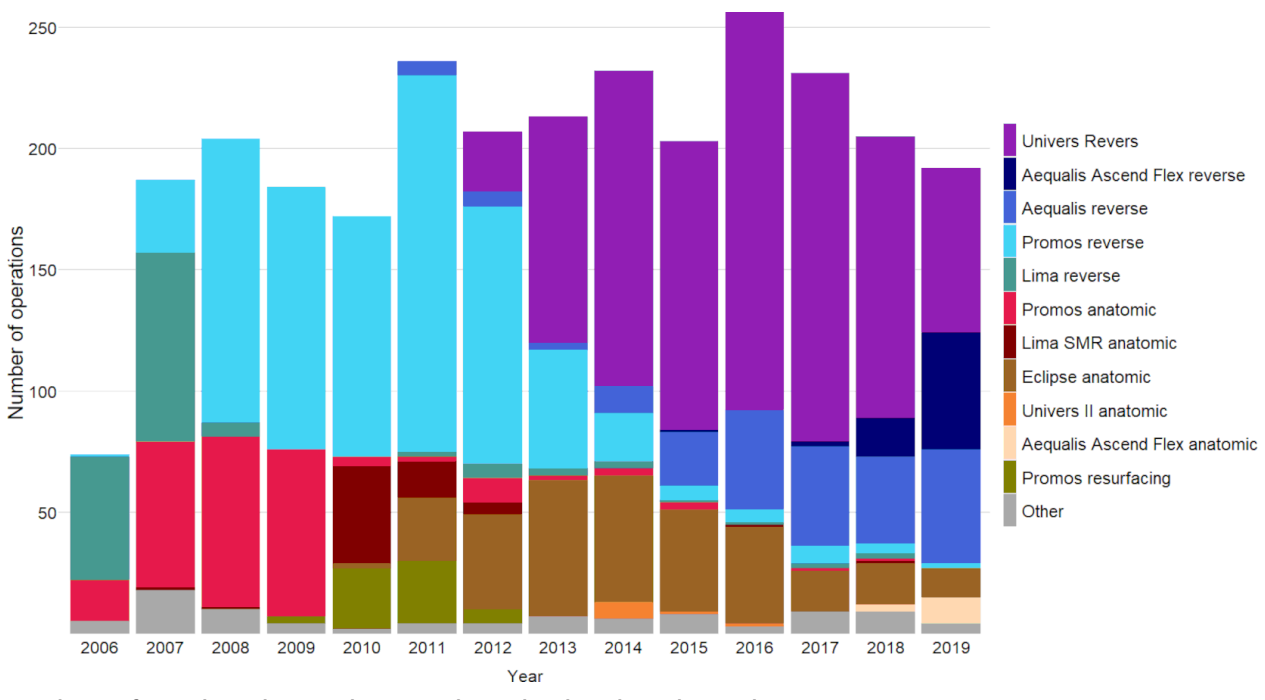

Figure 4 Annual number of total registered operations by implant brand.

\section{STRENGTHS AND LIMITATIONS}

Among the main strengths of the cohort are high coverage, a detailed description of the operation by the surgeon, use of validated outcome tools and internationally accepted core sets, consistent clinical, patient-reported and radiographic follow-up, and a relatively long follow-up time with some patients approaching the 15years follow-up landmark. One weakness of the cohort is lack of linkage with exact data on deaths which makes the distinction between deceased and lost to follow-up sometimes challenging. In addition, currently there is no systematic evaluation of the postoperative physical therapy. A general challenge stems from the fact that more than $60 \%$ of cohort participants are older than 70 years old. The progressively deteriorating general and cognitive health naturally diminishes long-term follow-up and retention rates. However, this challenge is shared by all geriatric cohorts. Over the years we learnt that patients who are unable to travel for a

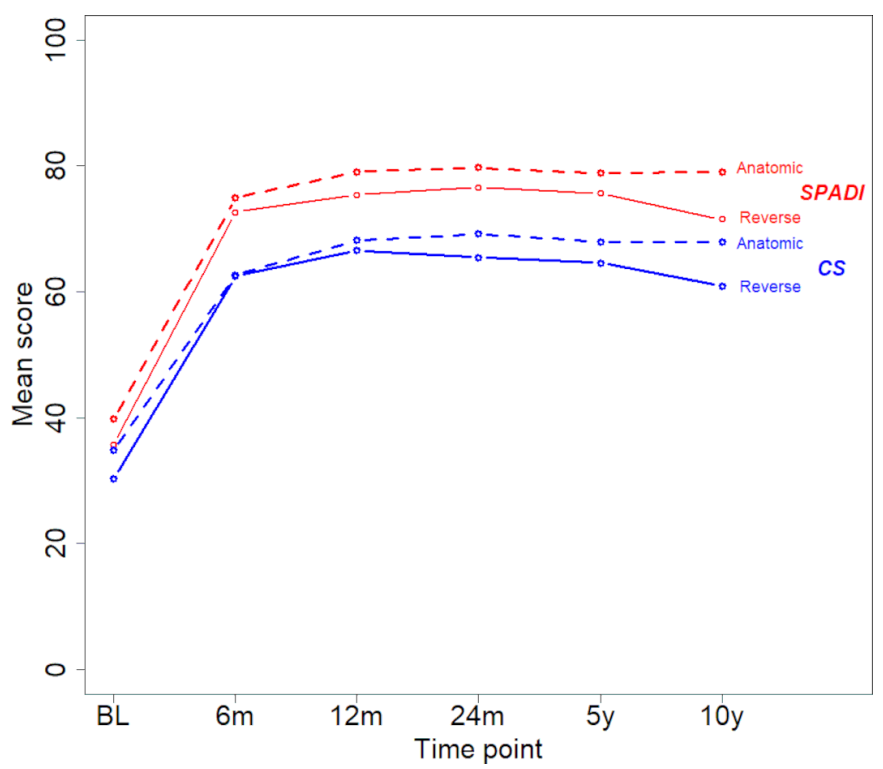

Figure 5 Changes in Shoulder Pain and Disability Index (SPADI) and the Constant Score (CS) over time by implant type. clinical visit will often agree to remain in the cohort and only complete the questionnaires, still providing useful information on patient-reported outcomes. Finally, the optimal and most clinically relevant and cost-effective follow-up schedule is not carved in stone. Since the primary focus of the cohort is on long-term outcome trajectories, our experience showed that the 12-month physical examination has limited clinical relevance for the registry. As a result, since November 2019 it was no longer required for a systematic registry documentation, but became optional, as per discretion of the treating surgeon.

\section{FUTURE PLANS}

A major long-term goal is development of a data representation system that will support real-time clinical decisions based on the registry data. With this system, the expected pain reduction, rate of functional recovery and expected complication rates can be presented to the patient before the operation to support treatment decisions and manage expectations. According to our early prototype, cohort data are continuously downloaded from the REDCap server within short intervals. After processing and quality control with custom STATA scripts the most important scores are calculated. Data are then uploaded into a Power BI (Microsoft, USA) server which is available for the clinicians within the electronic medical record system (figure 6). For patients that are considering the operation, the median trajectories can be shown to manage expectation and to help the patient to better understand the expected improvement and to make an informed risk-benefit decision. For already operated patients, the individual recovery curve can be compared with the median of the cohort (for the same implant, age group and gender). This will allow the patient an objective benchmark against which the individual treatment result can be compared and if necessary additional treatment steps can be agreed on.

Another central aim of the cohort is to leverage the data for a cost-effectiveness analysis of TSA. On the data collection 


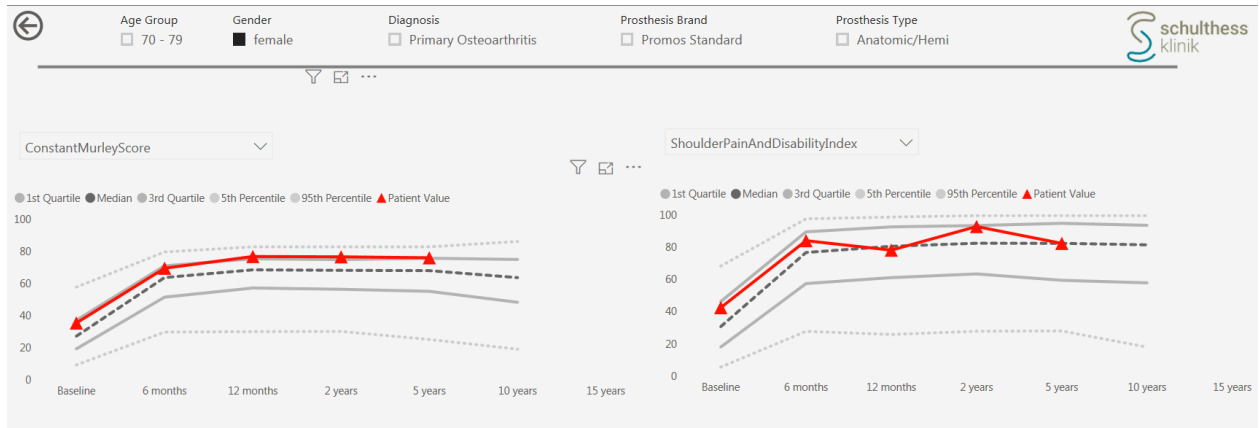

Figure 6 Screenshot from a prototype of the clinical expert system based on the Schulthess Shoulder Arthroplasty Registry cohort. Data from a single cohort participant is depicted with red triangles ('patient value').

front, the registry is in a transition phase toward an increased digitalisation. An option for receiving patient questionnaires via email is already available. However, implementation will depend on the technological literacy of each participant and complete abandonment of paper forms is currently unrealistic. Clinical examinations forms, which are currently collected on paper are planned to be entered directly into REDCap, although this will require an organisational solution that will reduce the already high documentation burden on the physicians.

Finally, the SAR is also expected to play a central role in the expansion of the Swiss Implant Register (SIRIS)—currently limited to knee, hip and spine- to shoulder arthroplasty implants as well. This will include contribution of data to periodic reports.

\section{PATIENT AND PUBLIC INVOLVEMENT}

Subjective patient satisfaction is a primary outcome in the cohort and is being assessed in periodic questionnaires. In addition to questionnaires, patient representative group is planned to be formed that will help the research teams to identify the most important research questions for our patients. Patient involvement is also essential for the development of the clinical expert system and one of the next steps will be to receive feedback from patients about the most accessible presentation of the data.

\section{COLLABORATION}

The steering committee of the SAR is open for collaboration with national and international partners. SAR board members regularly partake in International Shoulder Arthroplasty Consortium, which is part of the International Society of Arthroplasty Registries (www.isarhome.org).

Contributors AM, LA and H-KS initiated the study and drafted the manuscript. CK, $\mathrm{H}-\mathrm{KS}, \mathrm{BS}$ and BWeber contributed with design, maintenance and data management. H-KS, CK, FM, MF, MG, CJ, BWirth, BWeber, BS, MS contributed with data. AM and LA analysed the data. All authors revised the manuscript and approved the final version to be published.

Funding This work was supported by the Wilhelm Schulthess Foundation and by the Schwyzer Foundation.

Competing interests None declared.

Patient consent for publication Not required.
Ethics approval This study was approved by the Ethical Committee of Canton Zürich (KEK-ZH-Nr. 2014-0483). All participants provided informed consent (see online supplemental files 1 and 2).

Provenance and peer review Not commissioned; externally peer reviewed.

Data availability statement External researchers are encouraged to pair with a collaboration partner within the Schulthess Klinik. A proposal is then submitted to the SAR steering committee that is ranked on clinical relevance, novelty, feasibility, methodological robustness and on whether that data request competes with an ongoing project at the Schulthess Klinik. Following an approval of a multi-centre collaboration by the cohort steering committee aggregated and/or anonymised data can be shared for the specified collaboration, contingent on approval by the cantonal ethical committee. For more information on collaboration please contact the corresponding author.

Supplemental material This content has been supplied by the author(s). It has not been vetted by BMJ Publishing Group Limited (BMJ) and may not have been peer-reviewed. Any opinions or recommendations discussed are solely those of the author(s) and are not endorsed by BMJ. BMJ disclaims all liability and responsibility arising from any reliance placed on the content. Where the content includes any translated material, BMJ does not warrant the accuracy and reliability of the translations (including but not limited to local regulations, clinical guidelines, terminology, drug names and drug dosages), and is not responsible for any error and/or omissions arising from translation and adaptation or otherwise.

Open access This is an open access article distributed in accordance with the Creative Commons Attribution Non Commercial (CC BY-NC 4.0) license, which permits others to distribute, remix, adapt, build upon this work non-commercially, and license their derivative works on different terms, provided the original work is properly cited, appropriate credit is given, any changes made indicated, and the use is non-commercial. See: http://creativecommons.org/licenses/by-nc/4.0/.

ORCID iDs

Alex Marzel http://orcid.org/0000-0002-4795-6224

Laurent Audigé http://orcid.org/0000-0003-3962-3996

\section{REFERENCES}

1 Wall B, Nové-Josserand L, O'Connor DP, et al. Reverse total shoulder arthroplasty: a review of results according to etiology. J Bone Joint Surg Am 2007;89:1476-85.

2 Lin DJ, Wong TT, Kazam JK. Shoulder arthroplasty, from indications to complications: what the radiologist needs to know. Radiographics 2016;36:192-208.

3 Wierks C, Skolasky RL, Ji JH, et al. Reverse total shoulder replacement: intraoperative and early postoperative complications. Clin Orthop Relat Res 2009;467:225-34.

4 Buck FM, Jost B, Hodler J. Shoulder arthroplasty. Eur Radiol 2008;18:2937-48.

5 Ackland DC, Patel M, Knox D. Prosthesis design and placement in reverse total shoulder arthroplasty. J Orthop Surg Res 2015;10:101.

6 Torrens C, Guirro P, Miquel J, et al. Influence of glenosphere size on the development of scapular notching: a prospective randomized study. J Shoulder Elbow Surg 2016;25:1735-41.

7 Kolling C, Simmen BR, Labek G, et al. Key factors for a successful national arthroplasty register. J Bone Joint Surg Br 2007;89:1567-73. 
8 Audigé L, Graf L, Flury M, et al. Functional improvement is sustained following anatomical and reverse shoulder arthroplasty for fracture sequelae: a registry-based analysis. Arch Orthop Trauma Surg 2019;139:1561-9.

9 Kolling C, Borovac M, Audigé L, et al. Return to sports after reverse shoulder arthroplasty-the Swiss perspective. Int Orthop 2018:42:1129-35.

10 Simmen BR, Angst F, Schwyzer H-K, et al. A concept for comprehensively measuring health, function and quality of life following orthopaedic interventions of the upper extremity. Arch Orthop Trauma Surg 2009;129:113-8.

11 Spormann C, Durchholz H, Audigé L, et al. Patterns of proximal humeral bone resorption after total shoulder arthroplasty with an uncemented rectangular stem. J Shoulder Elbow Surg 2014;23:1028-35.

12 Angst F, Pap G, Mannion AF, et al. Comprehensive assessment of clinical outcome and quality of life after total shoulder arthroplasty: usefulness and validity of subjective outcome measures. Arthritis Rheum 2004;51:819-28.

13 Page RS, Navarro RA, Salomonsson B. Establishing an international shoulder arthroplasty Consortium. J Shoulder Elbow Surg 2014;23:1081-2.

14 Wirth B, Kolling C, Schwyzer H-K, et al. Risk of insufficient internal rotation after bilateral reverse shoulder arthroplasty: clinical and patient-reported outcome in 57 patients. J Shoulder Elbow Surg 2016;25:1146-54.

15 Jain NB, Wilcox RB, Katz JN, et al. Clinical examination of the rotator cuff. Pm R 2013;5:45-56.

16 Constant CR, Gerber C, Emery RJH, et al. A review of the constant score: modifications and guidelines for its use. J Shoulder Elbow Surg 2008; 17:355-61.

17 Constant CR. [Assessment of shoulder function]. Orthopade 1991;20:289-94.

18 Beaton DE, Wright JG, Katz JN, et al. Development of the QuickDASH: comparison of three item-reduction approaches. J Bone Joint Surg Am 2005;87:1038-46.

19 Angst F, Schwyzer H-K, Aeschlimann A, et al. Measures of adult shoulder function: disabilities of the arm, shoulder, and hand questionnaire (DASH) and its short version (QuickDASH), shoulder pain and disability index (SPADI), American shoulder and elbow surgeons (ases) Society standardized shoulder assessment form, constant (Murley) score (CS), simple shoulder test (sst), Oxford shoulder score (OSS), shoulder disability questionnaire (SDQ), and Western Ontario shoulder instability index (WOSI). Arthritis Care Res 2011;63:S174-88.

20 Angst F, Goldhahn J, Drerup S, et al. How sharp is the short QuickDASH? A refined content and validity analysis of the short form of the disabilities of the shoulder, arm and hand questionnaire in the strata of symptoms and function and specific joint conditions. Qual Life Res 2009;18:1043-51.

21 Angst F, Goldhahn J, Pap G, et al. Cross-Cultural adaptation, reliability and validity of the German shoulder pain and disability index (SPADI). Rheumatology 2007:46:87-92.

22 Gilbart MK, Gerber C. Comparison of the subjective shoulder value and the constant score. J Shoulder Elbow Surg 2007;16:717-21.

23 EuroQol Group. EuroQol-a new facility for the measurement of health-related quality of life. Health Policy 1990;16:199-208.

24 Janssen MF, Birnie E, Haagsma JA, et al. Comparing the standard EQ-5D three-level system with a five-level version. Value Health 2008;11:275-84.
25 Herdman M, Gudex C, Lloyd A, et al. Development and preliminary testing of the new five-level version of EQ-5D (EQ-5D-5L). Qual Life Res 2011;20:1727-36.

26 Audigé L, Schwyzer H-K, Shoulder Arthroplasty Core Event Set (SA CES) Consensus Panel. Core set of unfavorable events of shoulder arthroplasty: an international Delphi consensus process. J Shoulder Elbow Surg 2019;28:2061-71.

27 Audigé L, Goldhahn S, Daigl M, et al. How to document and report orthopedic complications in clinical studies? A proposal for standardization. Arch Orthop Trauma Surg 2014;134:269-75.

28 Rasmussen JV, Brorson S, Hallan G, et al. Is it feasible to merge data from national shoulder registries? a new collaboration within the Nordic arthroplasty register association. J Shoulder Elbow Surg 2016;25:e369-77.

29 Durchholz H, Salomonsson B, Moroder P, et al. Core set of radiographic parameters for shoulder arthroplasty monitoring: criteria defined by an international Delphi consensus process. JB JS Open Access 2019;4:e0025.

30 Harris PA, Taylor R, Thielke R, et al. Research electronic data capture (REDCap)--a metadata-driven methodology and workflow process for providing translational research informatics support. $J$ Biomed Inform 2009;42:377-81.

31 Haebich SJ, Mark P, Khan RJK, et al. The influence of obesity on hip pain, function, and satisfaction 10 years following total hip arthroplasty. J Arthroplasty 2020;35:818-23.

32 Schrøder HM, Berthelsen A, Hassani G, et al. Cementless porouscoated total knee arthroplasty: 10-year results in a consecutive series. J Arthroplasty 2001;16:559-67.

33 Eurostat. Healthy life years at age 65 by sex, 2020. Available: https:// ec.europa.eu/eurostat/databrowser/view/tepsr_sp320/default/table? lang=en [Accessed 29 Sep 2020].

34 Gerber C, Canonica S, Catanzaro S, et al. Longitudinal observational study of reverse total shoulder arthroplasty for irreparable rotator cuff dysfunction: results after 15 years. J Shoulder Elbow Surg 2018;27:831-8

35 C Glanzmann M, Kolling C, Schwyzer H-K, et al. Radiological and functional 24-month outcomes of resurfacing versus stemmed anatomic total shoulder arthroplasty. Int Orthop 2017;41:375-84.

36 Müller AM, Born M, Jung C, et al. Glenosphere size in reverse shoulder arthroplasty: is larger better for external rotation and abduction strength? J Shoulder Elbow Surg 2018;27:44-52.

37 Schwyzer H-K, Marzel A, Wirth B, et al. Short-term safety, function, and quality of life in patients treated with Univers Revers prosthesis: a multicenter 2-year follow-up case series. J Shoulder Elbow Surg 2020;29:2282-91.

38 Flury M, Kwisda S, Kolling C, et al. Latissimus dorsi muscle transfer reduces external rotation deficit at the cost of internal rotation in reverse shoulder arthroplasty patients: a cohort study. J Shoulder Elbow Surg 2019;28:56-64

39 Schneider MM, Toft F, Kolling C, et al. Limited reliability of grading scapular notching according to Nerot-Sirveaux on anteroposterior radiographs. Arch Orthop Trauma Surg 2019;139:7-13.

40 Glanzmann MC, Audigé L, Schwyzer H-K, et al. Re-intervention and revision rates following primary reverse total shoulder arthroplasty - review of a local shoulder arthroplasty registry. Int Orthop 2020;44:2365-70.

41 Glanzmann MC, Kolling C, Schwyzer H-K, et al. Conversion to hemiarthroplasty as a salvage procedure for failed reverse shoulder arthroplasty. J Shoulder Elbow Surg 2016;25:1795-802. 